\title{
Examining the economic impact of transport complex economies
}

\author{
Y. H. Venus Lun ${ }^{1 *}$, John Carlton ${ }^{2}$ and Khaild Bichou ${ }^{2}$
}

\author{
* Correspondence: \\ venus.lun@polyu.edu.hk \\ ${ }^{1}$ Department of Logistics and \\ Maritime Studies, Shipping Research \\ Centre, The Hong Kong Polytechnic \\ University, Hung Hom, Hong Kong \\ Full list of author information is \\ available at the end of the article
}

\begin{abstract}
Transport complex economies (TCEs), which comprise both upstream and downstream firms in the transport chain that conduct shipping and trade-related activities, can be desirable locations for port users (e.g., traders, logistics service providers, shipping lines and terminal operators) to perform their business activities. To explore TCEs, this study identifies trade facilitation measures at both the macro and micro levels to enhance regional performance. Hypotheses have been developed to build a theoretical model to illustrate the relationship between trade facilitation activities and trade costs. The economic outcomes are also examined in the theoretical model. To validate the proposed model, we have collected data from the World Bank and employed structural equation modelling. The result suggests that trade facilitation measures are negatively associated with trade cost. The result also suggests that the trade facilitation measures of a region is positively associated with its economic performance. Based on the findings, users can formulate effective and efficient strategies to select a location for their firm to conduct business activities. The findings illustrate the importance of the development of social capital for trade facilitation from the perspective of policy makers.
\end{abstract}

\section{Introduction}

The growing importance of global competition in international business has stimulated research in the areas of business studies to economic geography on the topic of location decision (Anokhin \& Wincent 2012). From the perspective of international business management, location decision is an important strategic decision as it involves a significant amount of resource commitment when investing in a particular region. Some researchers have also conducted studies on location avoidance to reduce the risk of wrong decisions (Schotter \& Beamish 2013). The concept of location (i.e., why and where firms conduct business activities in a particular region) has been a topic of interest (see Alcacer \& Chung 2007 Lorenen \& Mudambi 2013). Since the 1920s (Marshall 1920), topics such as economic agglomeration and location strategy have been examined from various perspectives. The growth of regions and economic development are also linked to external economies of scale when co-location is taken into consideration. Some studies have also taken a step further to examine co-located buyers and suppliers. According to Ganotakis \& Love (2012), global actors (e.g., traders involved in trading activities, logistics service providers who provide logistics related supporting services, liner shipping companies that provide regular sea transport services, terminal

(C) 2016 The Author(s). Open Access This article is distributed under the terms of the Creative Commons Attribution 4.0 International License (http://creativecommons.org/licenses/by/4.0/), which permits unrestricted use, distribution, and reproduction in any medium, provided you give appropriate credit to the original author(s) and the source, provide a link to the Creative Commons license, and indicate if changes were made. 
operators who handle containers and ships) who conduct their trading activities internationally have higher levels of growth and productivity.

Social capital, which is used to describe relational resources and value creation (Tsai \& Ghoshal 1998), has been applied in a wide range of social phenomena, particularly relations beyond the firm. Studies on social capital are mainly concerned with "the significance of relationships of resources for various action" (Barker 1990). The existence of such relationships or networks can be driven by resource-dependency, i.e., actors who are network members provide functions that are complementary to other actors in the network and synergistic with their contributions (Richardson 1972). Social capital can also be applicable to regional location selection, in that actors select locations with extensive networks to conduct their business, and the economic performance of such locations is expected to be better. For instance, liner shipping companies and container terminals operate in the same locations to receive containers and load/discharge containers on/from ships. At the same time, traders also select these locations to conduct their business activities because of the availability of transport related services to facilitate trading activities. Social capital can also include policy measures that facilitate the development of trading activities. For example, free trade ports and eliminating of taxes for trading activities will attract actors to establish and develop their business operations.

International shipping and transport operations are one of the most globalized industries in the world. Shipping activities are closely linked to international trade. Industrialization and globalization have bolstered global trade. Shipping and trade related activities contribute to economic development, e.g., trade and logistics activities contribute to one quarter of the GDP of Hong Kong. Managers make location decision to select appropriate location to perform their business operations. Location decision is crucial to continuing economic growth. Although location decision has been widely address in logistics related studies, the concept of transport complex economy (TCE) has not been adequately addressed. TCEs are "an economy that emerges from the joint location of transport-related activities that have substantial trading links with one another" (Lun et al. 2011a).

TCEs comprise various users of shipping and trade related activities, including trading, transport operations, logistics services, terminal operations, shipping management, and other related support services. These inter-organizational related activities are connected in terms of trading links and highly correlated with the economic performance of the region. These patterns of trading relations have considerable links with social capital. Grounded from the concept of social capital, TCEs have become an important topic that warrant further examination. This study therefore extends this line of research with the following objectives:

1. to identify macro level trade facilitation (TF-MA) and micro level trade facilitation (TF-MI) activities in the development of TCEs,

2. to build and empirically validate a theoretical model that will illustrate the relationship between TF-MA and TF-MI and their association with trade cost and economic performance,

3. to examine the implications of TCEs from the perspective of regional competitiveness, and 
4. to provide managerial guidelines for managers to make their location decision, and policy implications for policy makers to develop TCEs.

\section{Conceptualization and hypotheses development}

\section{Review on social capital}

There are a number of definitions for social capital. Nahapiet \& Ghoshal (1998) defined social capital as assets that may be mobilized through a network. According to Robbins \& Pettinicchio (2012), social capital is defined as the objective associations of a particular type among individuals that foster collective action. Barker (1990) viewed social capital as a resource that actors have derived from a specific social structure and then use to pursue their interests. Pennar (1997) defined social capital as a web of social relationships that influence individual behaviour and thereby affect economic growth. Porte (1998) saw social capital as the ability of actors to secure benefits by virtue of their membership in a social network or other types of social structures. In this study, we have defined social capital as a resource that actors in the shipping industry derive from the shipping related network to enhance economic performance of a region.

The concept of social capital has been popularly used in a variety of research to answer a range of questions. Social capital is useful for explaining a number of situations that range from the level of the firm to the national level. The breadth of the concept of social capital demonstrates that social ties of one kind (e.g., shipping and transport operations in a region) can be used for different purposes (e.g., influence location decision at the firm level and enhance economic performance at the national level). Adler \& Kwon (2002) used the "validity challenge" to conceptualize a framework that integrates various streams of social capital research, which stimulated dialogue across various perspectives and defined social capital as "the goodwill available to groups or individuals". Social capital stems from the social structure where actors are located, and available to them by virtue of ties that have been already established. The key features of TCEs include the presence of: (1) clusters of linked industries, and (2) a set of identifiable and stable business relations among actors that are engaged in shipping and trading activities. A typical TCE, e.g., Hong Kong, comprises various firms, such as traders, logistics service providers, shipping firms, terminal operators, truckers, feeder operators, and other related commercial agents. These firms are from linked industries (e.g., trading and transport) that engage in related activities. These inter-organizational relations are primarily developed in terms of trading links. The patterns of such trading transactions govern the decisions of business enterprises as to where to locate.

The operations of international businesses have become very much linked. These linkages are related to international trade activities as goods are produced in one country and consumed in another country. Shipping and trading centres are located in TCEs. Connectivity, which measures the extent to which the components of a network are connected to one another, is a key factor that affects the importance of TCEs. The strategic importance of TCEs is affected by the factors of location, accessibility, and infrastructure (Lun et al. 2010). A TCE comprises a set of transport infrastructures that take advantage of their corresponding geographical location to provide a high level of 
accessibility for connecting with trading partners. Accessibility, which refers to the extent to which a user can obtain the required resources at the time that they are needed, is the cornerstone of the competitiveness of TCEs. For instance, a TCE needs to access water to provide sea transport services. Connection with the hinterland, which is "the area where the demand for cargo movement is generated" and foreland, which is "the cargo destinations that are connected by shipping services from the cargo sources" (Rodrigue \& Notteboom 2010) is also essential for nurturing the development of TCEs.

In international business operations, production and consumption activities are spanning national borders. Goods move along a network of shipping nodes and links (Lun \& Browne 2009). The nodes are physical locations (e.g., container terminals and distribution centres) where goods are handled and transferred from one transport mode to another (Lun \& Cariou 2009). The links between nodes are connected by infrastructure components on which various transport modes operate. Along the shipping chain, actors involved in upstream and downstream activities work with each other (Lun et al. 2013a). For a trading region, actors (e.g., traders, logistics service providers, terminal operators, and shipping lines) in the network conduct business activities (Lun et al. 2013b). TCEs are a phenomenon that explains why traders and transport service providers are located in the same area. The success of a TCE is closely linked to the level of competition from rivals. A TCE contributes to regional competitiveness in several important ways. First, the geographical concentration of TCE users allows close linkages with business partners and related specialized resources. As users can access a well-established pool of resources, a TCE allows new entrances into the industry and reduces barriers to conducting shipping and trade related activities. Furthermore, the concentration of an industry facilitates knowledge transfer and market information spill overs among users in the TCE, hence facilitating industrial growth in the region. With vibrant inter-firm activities, ideas are quickly spread among neighbouring firms.

To examine the drivers that create social capital, Adler \& Kwon (2002) proposed an "opportunity-motivation-ability" framework. The network of social ties of an actor creates opportunities for social capital transactions. External ties to others give actors in a particular region the opportunity to gain access to new markets, reduce operating costs, and generate greater profits. Coleman (1998) argued that the extent to which actors are connected or interact affect the strength of social capital. The motivating factors for actors to join together and develop social ties are trust and associability. Social capital transforms actors from taking individual action to collective action to achieve common benefits. Trust is essential for actors to work closely together to take collective action. In addition, associability (Leana \& Van Buren 1999), which is defined as "the willingness and ability of actors to define collective goals that are then enacted collectively", is important for social capital. From the perspective of social capital, ability refers to "competencies at the nodes of the network". Associability comprises "the motivation and ability of a collectivity to define and enact its goals". The abilities of actors in a network are complements to social capital (Poetes 1998). In the context of trade facilitation, ties to the shipping industry provide valuable opportunities for traders to rapidly obtain information on shipping operations to provide better services to transport goods. In the context of TCEs, the ability of logistics service providers to provide high quality and low cost logistics services is important for traders to conduct their trading 
activities in a specific location. Social capital is the resource that facilitates the development of TCEs and associated with economic performance.

\section{Hypotheses development Trade facilitation}

The concept of social capital is useful for explaining the application of location strategy. When selecting a location to conduct trading related activities, business firms tend to select a region with resources that allow them to reduce their trade cost. At the regional or national level, policy makers have developed measures to attract business operators to invest in a certain location by improving the shipping networks to reduce trade cost so as to enhance economic performance. The two dimensions of location are place and space. According to Beugelsdijk \& Mudambi (2012), place is a "geographical unit of analysis" and space is spatial variation which is "any characteristic that generates variation among places". Spatial variation can be viewed at both the macro and micro levels of economic activities. In a highly competitive economy, policy makers play an important role in developing trade facilitation measures to boost trade related activities at the macro level (Loannou \& Serafeim 2012). For instance, the efficiency of customs and border management clearance is an effective measure that traders use to gauge the transport goods for international trade. To enhance transport related activities to provide logistics services that enhance the efficiency of trade related activities, it is desirable to provide high quality trade and transport infrastructures. The availability of TF-MA is therefore important for actors in their decision of selecting a location to conduct their business activities.

According to the World Bank, the Logistics Performance Index (LPI) consists of six items (source: http://lpi.worldbank.org). Two of the items can be categorized as TF-MA. The other four items are adapted from firms that conduct business operations in a region. These four items can therefore be classified as TF-MI. According to the opportunitymotivation-ability framework (Adler \& Kwon 2002), the network of social ties of an actor creates the opportunity to enhance trading and related business transactions. This opportunity can be the motivation for actors to create social ties (Coleman 1998). Hence, actors in a region are willing to take action for collective action to achieve common benefits (Leana \& Van Buren 1999). As a result, actors in a region are competent in conducting their business operations and possess the ability to provide services that facilitate trading and related activities (Poetes 1998).

In addition to TF-MA, the availability of TF-MI resources plays an essential role when actors are selecting a location to conduct their business activities. The need for resources to perform trade related activities drive actors to collaborate beyond their organizational boundaries to attain cost and service advantages from TF-MI (Lun et al. 2011b). TCEs with better performance in trade facilitation operations attract more actors to select their location to conduct operations. As a result, both TF-MA at the macro level and TF-MI at the micro level are essential components of TCEs. These two variables are associated. Hence, the following hypothesis is proposed:

\section{Hypothesis 1: TF-MA and TF-MI are positively associated.}

\section{Trade cost}

Social capital facilitates the access of information and updates on the latest operations in the field to enhance business operations (Coleman 1998). Information transfer 
among actors in the industry who are located in the same region facilitates firms to better understand industry requirements and provide better services to serve their customers (Uzzi 1997). Effective information flow among the actors in the trade and logistics industries can also enhance their ability to adopt technology that would provide track and trace services. Traders can benefit from the logistics network to obtain high quality logistics services. With the existing logistical networks, traders can easily coordinate with shipping lines and logistics service providers to arrange shipments at competitive prices. Social capital bridges disconnected actors in the industry which allows them to connect with others (Burt 1997). When traders support the operations of a TCE with sufficient cargo volume, service providers in the industry can provide high sailing frequencies so that shipments reach destinations within the expected delivery times.

From the perspective of TF-MA, the benefits that social capital can provide include information and influence (Samdefir \& Laumann 1988). For instance, effective information improves the efficiency of customs and border clearance. A typical example of the benefit from influence is high quality trade and transport infrastructure which positively influence the efficiency of transport operations. From the perspective of TF-MI, the benefits that social capital can provide originate from four approaches: communitarian, networks, institutional and synergy (Woolcock \& Narayan 2000). The communitarian view is measured by the number and density of local groups, and in this context, in terms of frequency, e.g., shipments can reach consignees within expected delivery times because of high sailing frequencies. The network view refers to the relations within and among actors. In the context of TF-MI, a shipping network with actors who closely work with others will better perform cargo tracking and provide accurate and timely information to their customers. The institutional view argues that "the capacity of actors to act in their collective interest depends on the quality of the formal institutions under which they reside" (Adger 2009). The level of service of a TCE is high when all of the actors in the network provide high quality services. Synergy refers to mutually supportive relations and promotion of complementarities. For instance, traders can easily arrange for competitively priced shipments in a TCE when shipping and logistics service providers are supportive in the performing of shipping related activities.

Social capital is an important resource that leads to a number of positive outcomes. According to Portugal-Perez \& Wilson (2012), trade facilitation is "the set of policies aiming at reducing export and import costs". Hence, trade cost is an important variable that needs to be taken into account in TCEs. Trade cost consists of the costs to export and import. Transaction cost, which refers to costs incurred in the performing of trading activities, is useful for examining performance outcomes. The transaction cost for actors is lower if their business operations are located in efficient TCEs. In selecting a location to conduct trading related activities, it is recommended that a strategy-performance relationship is used to make sound inferences (Martin 2013). Brouthers (2002) examined performance outcomes by integrating transaction cost and institutional perspectives. The scope of the institutional explanation extends beyond the level of the firm (Brouthers 2013). Social capital involves TF-MA and TFMI. When a region has social capital, its trade costs tend to be lower. Hence, the following hypotheses are developed:

Hypothesis 2.1: TF-MA and trade cost are negatively associated. 
Hypothesis 2.2: TF-MI and trade cost are negatively associated.

\section{Economic performance}

The international integration of trading and related activities has substantially increased in the past decades (Garrett 2009). The increased international integration of goods and services has contributed to economic development. One of the most important benefits of trade liberalization and trade facilitation is economic growth (Winters 2004). The development of TCEs can be a substantial means to enhance the regional competitiveness of a location. Regional competitiveness can be viewed as: (1) the ability of a region to provide integrated trading and related services that meet the needs of traders, and (2) a region that is able to generate relatively high income and high employment levels, while at the same time, face increasingly competitive pressure from their competitors (European Commission 1996).

The subject of performance is receiving increasing interest from both the academia and managers. In examining the contribution of TCEs, it is important to examine performance outcome. The GDP of a country reflects actual economic performance (Rawski 2001), and therefore GDP is commonly used at the regional or national level to examine economic growth and performance (Robbins \& Pettinicchio 2012). GDP per capital is a good indicator of economic performance (Chen et al. 2005). The development of TF-MA involves investment in social capital and will lead to the improvement of economic performance. Accordingly, the following hypothesis is proposed.

Hypothesis 3: TF-MA positively affects the economic performance of a country.

GDP is the sum of the gross value added to the economy. As TCEs focus on trading and related services, their share of services in GDP also plays an important role in examining the performance outcome of a country. Increases in the exchange of services through various trading activities may raise the productivity of firms. The competitiveness of firms depends on "the availability, cost and quality of producer services" (Eschenhach \& Hoekman 2006). If trade costs in a TCE are lower, the value added from service will be higher. Accordingly, the following hypothesis is suggested.

Hypothesis 4: Trade cost negatively influences the service orientation of a country.

A TCE with a lower operating cost and high level of TF-MI is an attractive place to conduct business operations. The existence of TF-MI reflects the increasing importance of the orientation towards service. Francois (1990) developed a model to illustrate the importance of service to economic growth. He argued that the increasing importance of the orientation towards service reflects modern business operations. To be competitive, firms need to devote effort and resources to perform their core business. The growth in the outsourcing of activities to external service providers indicates the importance of service. The outsourced activities range from the sourcing of parts and products to performing shipping and logistics operations. A TCE with a high level of TF-MI is capable of providing better services for serving actors and facilitating them to perform trading and related activities. To better understand the contribution of TCEs, it is therefore essential to examine the relationship between economic performance and economic activities (Banerjee \& Marcellino 2006). According to Ang (2006), the economic performance of a country will be better when their operating efficiency is higher. Hence, the following hypotheses are put forth.

Hypothesis 5.1: TF-MI positively affects the service orientation of a country. 
Hypothesis 5.2: The service orientation of a country positively affects its economic performance.

\section{Methodology}

The next step is to validate the above hypotheses to formulate our research model. In this study, we use SPSS AMOS software to conduct structural equation modelling (SEM). SEM is a statistical method designed to test a conceptual or theoretical model (Kaplan 2007). SEM is a combination of two components: (1) a measurement model that defines latent variables by using one or more observed variables, and (2) a structural regression model that links latent variables together (Kline 2011). SEM is widely used in empirical research for model specification. In SEM diagrams, latent variables are commonly shown as ovals and observed variables as rectangles. SEM provides numerical estimates for each of the parameters (arrows) in the model to indicate the strength of the relationships.

We used an empirical approach to collect secondary data published in 2012 for analysis from the World Bank. The secondary data analysis involved the analysis of an existing dataset, which had previously been collected by another researcher for different research questions (Miller \& Brewer 2003). The World Bank database provides a large volume of high-quality information as secondary data for researchers. In addition, the use of secondary data is essential since it may be difficult to conduct a new survey to obtain data such as GDP per capita. The key advantage of using secondary data is the breadth of the information available. In this study, the four-step secondary data analysis method proposed by Miller \& Brewer (2003) is adopted: (1) the research model is developed by establishing the hypotheses, (2) the population is specified with data obtained across 160 countries provided by the World Bank, (3) the variables (i.e., TFMA, TM-MI, trade cost and other economic performance indicators) are specified, and (4) the quantitative data that are the most appropriate for validating our proposed research model are specified.

The data collection process consisted of three stages. In the first stage, we identified the secondary data for measuring TF-MA and TF-MI published from the LPI of the World Bank (source: http://lpi.worldbank.org). The LPI comprises six items: (1) the efficiency of customs and border staff, (2) quality of trade and transport infrastructures including sea port, airport, road and rail, (3) ease of arranging competitively priced shipments, (4) competence and quality of the logistics services, (5) ability to track and trace, and (6) frequency that shipments reach consignees within the expected delivery times. The first two items (i.e., TF-MA01 and TF-MA02) were adopted as the measurement items of TF-MA and the remaining four items (i.e., TF-MI01, TF-MI02, TFMI03, and TF-MI04) were adopted as the measurement items of TF-MI. According to the World Bank, the LPI is an interactive benchmarking tool used to identify performance on trade logistics, and allows for comparisons across 160 countries. The LPI was based on a worldwide survey to provide feedback on the logistics friendliness of the countries where the respondents operate. Feedback from the respondents was supplemented with quantitative data on the performance of the six items of the LPI.

The second stage was to collect data from the World Bank to determine trade cost. Trade cost involves two measurement items: (1) the cost to export, and (2) the cost to import. According to data from the World Bank, the cost to export and cost to import 
include the fees levied on a 20-foot container in U.S. dollars. All of the fees associated with completing the procedures to export or import goods were included. These include costs for documents, administrative fees for customs clearance and technical control, customs broker fees, terminal handling charges and inland transport. The cost measure did not include tariffs or trade taxes. Only official costs were recorded.

The final stage was to collect the GDP per capita and value added from service which were obtained from the World Bank to evaluate the performance outcomes. The GDP per capita is gross domestic product divided by midyear population. GDP is the sum of the gross value added by all resident producers in the economy plus any product taxes and minus any subsidies not included in the value of the products. The GDP per capita was calculated without making deductions for depreciation of fabricated assets or the depletion and degradation of natural resources. The GDP was presented in current U.S. dollars. According to the World Bank, value added from service include wholesale and retail trade, transport, and government, financial, professional, and personal services. Also included are imputed bank service charges, import duties, and any statistical discrepancies noted by national compilers as well as discrepancies that arise from rescaling. Value added is the net output of a sector after adding up all outputs and subtracting intermediate inputs. The value added from service is calculated without making deductions for the depreciation of fabricated assets or depletion and degradation of natural resources.

\section{Data analysis and result}

The descriptive statistics of the study variables are shown in Table 1. To test the reliability of our study variables, we used Cronbach's alpha (Cronbach 1951) to evaluate their internal consistency. Cronbach's alpha is the most appropriate tool used to indicate the degree to which a set of items measure a single construct. According to the SPSS program, Cronbach's alpha can be written as "a function of the number of test items and the average inter-correlation among the items". Cronbach's alpha $(\alpha)$ is a coefficient of reliability (or consistency). The acceptable level is $\alpha>0.6$. The internal

Table 1 Descriptive statistics

\begin{tabular}{lllll}
\hline Descriptive statistic of TF-MA and TF-MI & Minimum & Maximum & Mean & Std. Deviation \\
& 1.33 & 4.04 & 2.5935 & 0.61682 \\
TF-MA01 & 1.35 & 4.34 & 2.6372 & 0.73167 \\
TF-MA02 & 1.33 & 3.86 & 2.8452 & 0.46954 \\
TF-MI01 & 1.33 & 4.32 & 2.7583 & 0.63635 \\
TF-MI02 & 1.17 & 4.27 & 2.9178 & 0.65002 \\
TF-MI03 & 1.38 & 4.58 & 3.4092 & 0.57496 \\
TF-MI04 & & & & \\
Descriptive statistic of trade cost & Minimum & Maximum & Mean & Std. Deviation \\
& 450 & 5902 & 1387 & 849 \\
Cost to export & 439 & 8525 & 1642 & 1179 \\
Cost to import & & & & \\
Descriptive statistic of economic performance & Minimum & Maximum & Mean & Std. Deviation \\
& 199 & 103574 & 12671 & 18332 \\
GDP per capita & -96 & 93 & 56 & 21 \\
Value added from service & & & & \\
\hline
\end{tabular}


consistency of the items to measure a construct is excellent when $\alpha>0.9$. According to the result shown on Table 2, $\alpha$ values for TF-MA is 0.969 , TF-MI is 0.944 , and trade cost is 0.963 . Hence, the reliability of these items for measuring the variables in this study is excellent.

The next step is to present the result of the SEM (as shown on Table 3). Hypothesis 1 is supported as TF-MA and TF-MI are positively associated with a coefficient of 0.979 . Hypotheses 2.1 and 2.2 are supported as cost trade is negatively associated with TF-MA and TF-MI with coefficients of -0.429 and -0.404 respectively. In addition, we examined the economic performance outcomes. Hypotheses 3 and 4 are supported as TF-MA positively affects the gross value added from service with a coefficient of 0.774 , and trade cost negatively affects value added from service with a coefficient of -0.193 . Hypotheses 5.1 and 5.2 are also supported as TF-MI positively affects value added with a coefficient of 0.349 , and value added from service positively affects gross value added with a coefficient of 0.107 . All of these causal relationships are significant with $p<0.001$. The research model based on the estimated paths of the SEM result is shown in Fig. 1.

It is important to examine the "fit" of an estimated model. Absolute fit indices provide the fundamental indication of how well the proposed model fits the data (McDonal \& Ho 2003). According to Hooper et al. 2008, absolute fit indices include the chi-square test and the root mean square error of approximation (RMSEA). The chi-square test is the most commonly used method to measure model fit. The chi-square value represents the difference between the observed covariance matrix and the predicted or model covariance matrix. The relative chi-square equals the chi-square $\left(x^{2}\right)$ divided by the degree of freedom $(d f)$. The criterion for acceptance of this index varies across researchers, which ranges from less than 2 to less than 5 (Schumacker \& Lomax 2004). In general, the value should be less than 3 (Kline 1998 and Tabachnick BG Fidell 2001). In our model, the result of the chi-square test is 2.6 (i.e. 78.596/30), which is an acceptable level. The RMSEA analyses the discrepancy between the hypothesised model with optimally chosen parameter estimates and the population covariance matrix (Hooper et al. 2008). The RMSEA ranges from 0 to 1 , with smaller values indicating better model fit. A value of 0.1 or less is indicative of acceptable model fit (Hu \& Bentler 1999). The value of RMSEA of our SEM model is 0.061 indicating that our model is acceptable.

According to Cheung \& Rensvold (2002), other important indexes to compare the target model with the null model are relative fit index (RFI), comparative fit index

Table 2 Study variables

\begin{tabular}{lllc}
\hline Construct & $\begin{array}{l}\text { Cronbach's } \\
\text { alpha (a) }\end{array}$ & Measurement item & $\begin{array}{c}\text { Loading } \\
(p<0.001)\end{array}$ \\
\hline TF-MA & 0.969 & TF-MA01: Efficiency of customs and border management clearance & 0.974 \\
& & TF-MA02: Quality of trade and transport infrastructure & 0.989 \\
TF-MI & \multirow{2}{*}{0.944} & TF-MI01: Ease of arranging competitively priced shipments & 0.909 \\
& & TF-M102: Competency and quality of logistics services & 0.983 \\
& & TF-MI03: Ability to track and trace & 0.963 \\
& & TF-M104: Frequency that shipments reach consignees within & 0.912 \\
Trade cost & 0.963 & expected delivery time & 0.962 \\
& & Cost to export per container & 0.971 \\
\hline
\end{tabular}


Table 3 Test result

\begin{tabular}{lll}
\hline Path & Estimate & Hypothesis \\
\hline GDP per capita $\leftarrow$ TF-MA & $0.774^{* * *}$ & $\mathrm{H} 3$ \\
GDP per capita $\leftarrow$ Value added from service & $0.107^{* * *}$ & $\mathrm{H} 5.2$ \\
Value added from service $\leftarrow$ Trade cost & $-0.193^{* * *}$ & $\mathrm{H} 4$ \\
Value added from service $\leftarrow$ TF-Ml & $0.349^{* * *}$ & $\mathrm{H} 5.1$ \\
TF-MA $\leftarrow \rightarrow$ TF-Ml & $0.979^{* * *}$ & $\mathrm{H} 1$ \\
TF-MA $\leftarrow \rightarrow$ Trade cost & $-0.429^{* * *}$ & $\mathrm{H} 2.1$ \\
Trade cost $\leftarrow \rightarrow$ TF-Ml & $-0.404^{* * *}$ & $\mathrm{H} 2.2$ \\
\hline
\end{tabular}

${ }^{* * *} p<0.001$

(CFI), normal fit index (NFI), and incremental fit index (IFI). The RFI is one of the most informative indices in SEM (Bollen 1986). The RFI is usually between 0 and 1 with 0 representing a poor fit and close to 1 representing a very good fit. In the RFI, a value of zero indicates the worst possible model and a value of one indicates the best possible model (Kenny \& McCoach 2003). The RFI value for our SEM is 0.966 which means that ours is a very good fitting model. The CFI is also known as the Bentler \& Bonett (1980) and Bentler (1990) comparative fit index. The CFI compares the fit of a target model to the fit of an independent model in which the variables are assumed to be uncorrelated. A value of CFI that approaches 1 indicates an acceptable fit. The CFI value for our SEM is 0.988 , which means an acceptable fit. The NFI is also known as the Bentler-Bonett (Bentler \& Bonett 1980) normed fit index. The fit index varies from

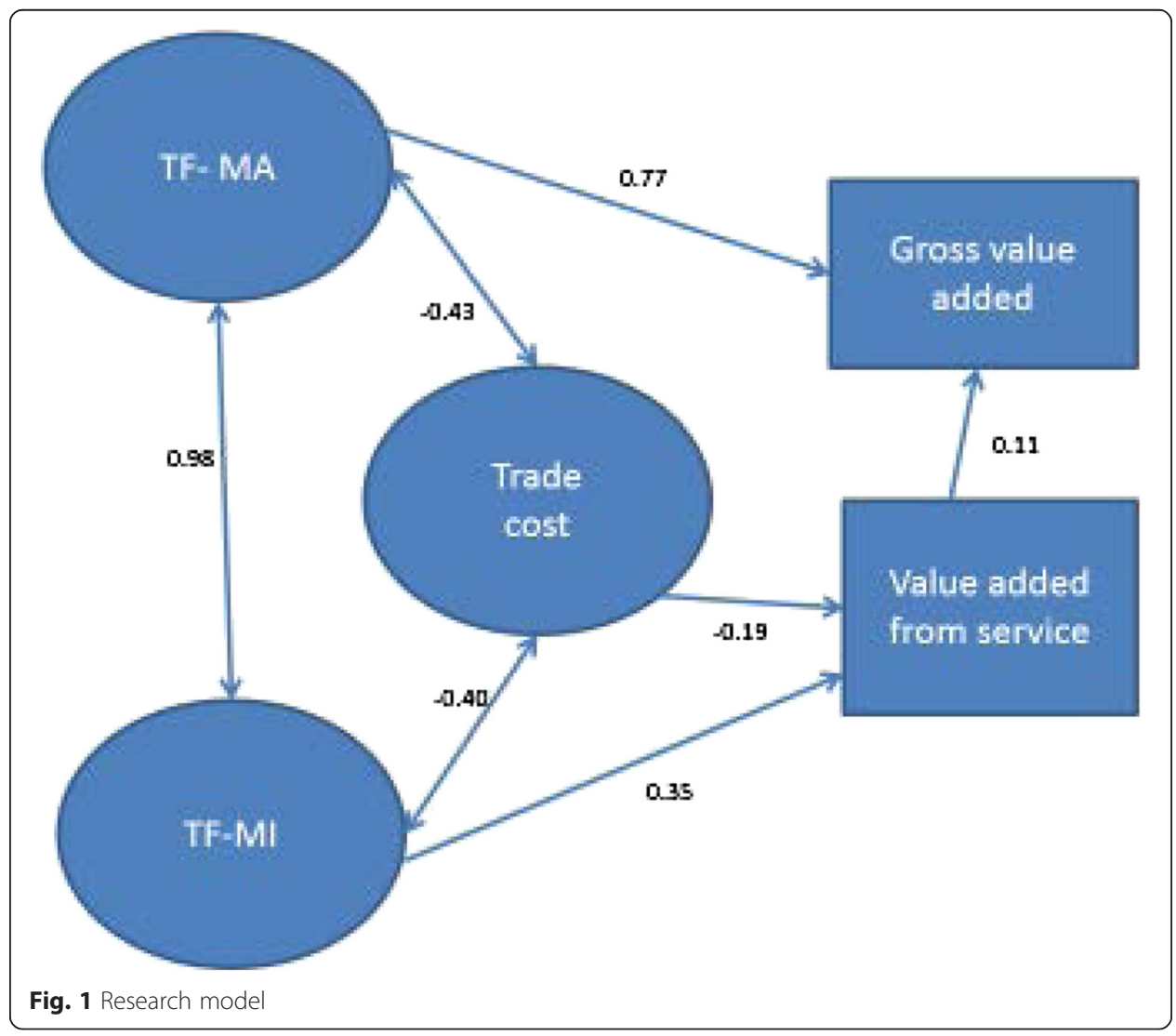


0 to 1 where 1 is ideal. The NFI equals the difference between the chi-square of the null model and the chi-square of the target model, divided by the chi-square of the null model. An NFI value that exceeds 0.90 (Byrne 1994) or 0.95 (Schumacker \& Lomax $2004)$ is acceptable. The value of the NFI for our SEM is 0.981 which indicates that the model of interest improves the fit by $98.1 \%$ relative to the null model. The TuckerLewis index (TLI) is similar to the NFI. The value of the TFI is usually lower than that of the NFI, but values over 0.90 or 0.95 are considered acceptable (e.g.,Hu \& Bentler 1999). The TLI value for our SEM is 0.978 , thus indicating that the model is acceptable. The IFI is also known as Bollen's incremental fit index (1989 and 1990). The IFI is based on the comparison of the fit of a substantive model to that of a null model (Widaman \& Thompson 2003). Although this index can exceed 1, values that exceed 0.90 are regarded as acceptable. The IFI value for our SEM is 0.988 , thus indicating that the model is acceptable.

The issue of validity is also important to examine. Construct validity is "the degree to which a test measures what it claims, or purports, to be measuring" (Brown 1996). Convergent validity and discriminant validity are the subtypes to make up construct validity. Convergent validity assesses "the degree to which two measures of the same concept are correlated" and discriminant validity examines "the degree to which two conceptually similar concepts are distinct" (Hair et al. 2006). In this study, correlation analysis was conducted to examine the convergent validity. According to Table 6, the measures of TF-MA (i.e. TF-MA01 and TF-MA02), TF-MI (i.e. TF-MI01, TF-MI02, TF-MI03, and TF-MI04), and trade cost (i.e. CE and CI) are correlated. We also divided the data of 160 countries into two groups. The first group is developed countries with GDP per capita higher than the mean value (i.e. > USD12671), and the second group is developing countries (with GDP per capita $<$ USD 12671). According to Tables 4 and 5 , the measures of TF-MA (i.e. TF-MA01 and TF-MA02), TF-MI (i.e. TF-MI01, TFMI02, TF-MI03, and TF-MI04), and trade cost (i.e. CE and CI) for both developed and developing countries are correlated. The result indicates that the convergent validity is established. Discriminant validity examines "whether concepts or measurements that are supposed to be unrelated are unrelated" (Campbell 1959). Expected cross validation index (ECVI) is useful to determine the discriminant validity. ECVI is "the average discrepancy in the fitted covariance matrices between two samples of equal sample size across all possible combinations of two samples from the same population" (West et al.

Table 4 Correlation matrix - developed countries

\begin{tabular}{llllllllll}
\hline & MA01 & MA02 & MI01 & MI02 & MI03 & MI04 & CE & Cl & GDP \\
\hline MA01 & 1.000 & & & & & & & \\
MA02 & $.924^{* *}$ & 1.000 & & & & & & \\
MI01 & $.711^{* *}$ & $.719^{* *}$ & 1.000 & & & & & \\
MI02 & $.872^{* *}$ & $.933^{* *}$ & $.789^{* *}$ & 1.000 & & & & \\
MI03 & $.761^{* *}$ & $.864^{* *}$ & $.804^{* *}$ & $.931^{* *}$ & 1.000 & & & \\
MI04 & $.898^{* *}$ & $876^{* *}$ & $656^{* *}$ & $844^{* *}$ & $767^{* *}$ & 1.000 & & \\
Cost to Export (CE) & $-.302^{*}$ & -.223 & -.081 & -.199 & -.111 & -.195 & 1.000 & \\
Cost to Import (Cl) & $-.356^{*}$ & -.260 & -.132 & -.219 & -.121 & -.236 & $.970^{* *}$ & 1.000 \\
GDP per capita (GDP) & $.654^{* *}$ & $.673^{* *}$ & $545^{* *}$ & $.560^{* *}$ & $.584^{* *}$ & $632^{* *}$ & 039 & -.010 & 1.000 \\
\hline **Correlation is significant at the 0.01 level (2-tailed) & & & & & & \\
*Correlation is significant at the 0.05 level (2-tailed) & & & & &
\end{tabular}


Table 5 Correlation matrix - developing countries

\begin{tabular}{|c|c|c|c|c|c|c|c|c|c|}
\hline & MA01 & MA02 & Ml01 & MI02 & $\mathrm{MlO3}$ & Ml04 & CE & $\mathrm{Cl}$ & GDP \\
\hline MA01 & 1.000 & & & & & & & & \\
\hline MA02 & $.888^{* *}$ & 1.000 & & & & & & & \\
\hline MI01 & $.681^{* *}$ & $.704^{* *}$ & 1.000 & & & & & & \\
\hline Ml02 & $.889^{* *}$ & $.924^{* *}$ & $.670^{* *}$ & 1.000 & & & & & \\
\hline MI03 & $.834^{* *}$ & $.822^{* *}$ & $.672^{* *}$ & $.861^{* *}$ & 1.000 & & & & \\
\hline MI04 & $.750^{* *}$ & $.745^{* *}$ & $.600^{* *}$ & $.788^{* *}$ & $.773^{* *}$ & 1.000 & & & \\
\hline CE & $-.299 * *$ & $-.353^{* *}$ & $-.214^{* *}$ & $-.303^{* *}$ & $-.286^{* *}$ & $-.248^{* *}$ & 1.000 & & \\
\hline $\mathrm{Cl}$ & $-.318^{* *}$ & $-.372^{* *}$ & $-.259^{* *}$ & $-.314^{* *}$ & $-.277^{* *}$ & $-.204^{* *}$ & $.932^{* *}$ & 1.000 & \\
\hline GDP & $.529^{* *}$ & $.600^{* *}$ & $.370^{* *}$ & $.560^{* *}$ & $.532^{* *}$ & $.475^{* *}$ & $-.189^{*}$ & $-.206^{*}$ & 1.000 \\
\hline
\end{tabular}

2012). The lower the value of ECVI, the better the model (Browne \& Cudeck 1993). The value of ECVI of this SEM is 0.299 , indicating that the model is acceptable.

\section{Discussion}

The contributions of this study can be viewed from both academic and practical perspectives. Academically, the result of this research contributes knowledge towards TCE and the use of trade facilitation activities to enhance economic performance. The findings of this study provide a comprehensive picture on the development of TCE and the linkage with economic performance. This study examines the key attributes of trade facilitation measures and investigates the performance outcomes. This study has developed a more systemic theory-driven model for the development of TCE than those previously found in the existing literature. Furthermore, a theory that explains the development of TCEs and the performance outcomes of TECs is established and empirically tested. Practically, the result of this study has significant managerial contributions because effective trade facilitation measures have been identified, which can be useful for traders and transport related operators in selecting a location to conduct their business operations and managing their shipping operations.

For the perspective of policy makers, the development of TCE is crucial to continuing economic development and sustainability. An efficient TCE, comprising both upstream and downstream firms in the transport chain to conduct shipping and trade-related activities, is a desirable arena for actors (e.g., traders, logistics service providers, shipping lines, and terminal operators) to perform their business activities. TCE contributes to regional competitiveness in three important ways. First, the geographical concentration of TCE users allows access to upstream and downstream business partners and related specialized resources. Second, TCE facilitates new entrances into the industry and reduces barriers to conduct related activities as users can access a well-established pool of resources. Finally, the concentration of an industry facilitates knowledge transfer and market information spill overs among users to enhance industrial growth. The findings of this study provide a useful insight for policy makers to enhance social capital of TFMA and TF-MI to improve the efficiency of TCE.

The efficiency of TCE affects the location decisions of international business operators. Location is important to TCE users because: (1) the localization of an industry provides support for specialized service providers to source inputs for their productive 
activities, (2) technological spill overs can be generated with the rapid diffusion of information where there is localized concentration of industry, and (3) the pooling of specialized workforces in a locality provides an adequate supply of human resources to facilitate the development of shipping and trade related activities. Such geographical concentration is internal to the shipping and trade sectors, but external to users who are operating in a TCE. The findings show the importance of the development of TFMA and TF-MI as social capital from the perspective of policy makers. To contribute to the formulation of measures to boost economic growth, this study identified both macro-level trade facilitating activities (TF-MA) and micro-level trade facilitating activities (TF-MI) that contribute to the development of a TCE. Findings of this study illustrate that both TF-MA and TF-MI are related with actors' business operations in terms of trade cost. Trade cost is lower if actors conduct their business activities in an efficient TCE. The findings provide justifications for firms to select particular locations to conduct their business operations. Based on the findings, managers can formulate effective and efficiency strategies to select locations for their firms to conduct their businesses. The result supports the argument that TF-MA and TF-MI positively affect the economic performance of an economy.

This study not provides a general model across countries. To better understand the difference between developing and developed countries to provide useful reference for policy makers for effective measures formulation, we also conducted a comparison between the two groups. Table 6 illustrates the overall result with negative correlation between trade facilitation activities (TF-MA and TF-MI) and trade cost. In general, the higher the level of trade facilitation, the lower the trade cost. For developing counties, trade facilitation activities (TF-MA and TF-MI) are negatively correlated with trade cost ( $\mathrm{CE}$ and $\mathrm{CI})$ on the one hand and positively correlated with economic performance on the other hand (see Table 5). The result indicates the importance of trade facilitation in TCE development, particularly for developing countries. For developed countries, trade facilitation activities (TF-MA and TF-MI) are positively correlated with economic performance but have no impact on trade cost (CE and CI) with the exception of TFMA01 (see Table 4). For developed countries with high cost for advanced infrastructure and business operations, the trade facilitation activity of efficiency of customs and border management clearance (TF-MA01) is an important social capital. It is desirable for policy makers to put effort to develop appropriate measures to attract business managers to make decision to situate their business operations and develop social

Table 6 Correlation matrix of the variables

\begin{tabular}{|c|c|c|c|c|c|c|c|c|}
\hline & MA01 & MA02 & MI01 & $\mathrm{MlO2}$ & $\mathrm{MIO3}$ & MI04 & CE & $\mathrm{Cl}$ \\
\hline MA01 & 1.000 & & & & & & & \\
\hline MA02 & $.888^{* *}$ & 1.000 & & & & & & \\
\hline Ml01 & $.681^{* *}$ & $.704^{* *}$ & 1.000 & & & & & \\
\hline Ml02 & $.889^{* *}$ & $.924^{* *}$ & $.670^{* *}$ & 1.000 & & & & \\
\hline MI03 & $.834^{* *}$ & $.822^{* *}$ & $.672^{* *}$ & $.861^{* *}$ & 1.000 & & & \\
\hline Ml04 & $.750^{* *}$ & $.745^{* *}$ & $.600^{* *}$ & $.788^{* *}$ & $.773^{* *}$ & 1.000 & & \\
\hline CE & $-.299 * *$ & $-.353^{* *}$ & $-.241^{*}$ & $-.303^{* *}$ & $-.286^{* *}$ & $-.248^{* *}$ & 1.000 & \\
\hline $\mathrm{Cl}$ & $-.318^{* *}$ & $-.372^{* *}$ & $-.259^{* *}$ & $-.314^{* *}$ & $-.277^{* *}$ & $-.204^{*}$ & $.932^{* *}$ & 1.000 \\
\hline
\end{tabular}


capital (i.e. resource that actors in the shipping industry derive from the shipping related network to enhance economic performance of a region).

\section{Conclusion}

In this study, hypotheses have been developed and tested by specifying the pathways with SEM. The result from the data analysis is used to validate the proposed model (i.e., Hypotheses 1, 2.1, 2.2, 3, 4, 5.1 and 5.2). This study is timely and important for facilitating TCE development for four reasons:

- First, due to the rapid globalization of productive activities and markets, as well as the continuing rise in global trade volume, it is anticipated that shipping activities will continue to grow at a fast pace. Shipping, logistics, and trade related activities will continue to bring many commercial opportunities to business firms. However, there is insufficient knowledge on the requirements for the development of TCEs and their economic implications. This research is therefore valuable to policy makers, as it identifies both the macro-level and micro-level (through the validation of Hypothesis 1) trade facilitation activities that contribute to the development of TCEs. Existing studies (e.g., LPI) focus on benchmarking among countries. This study extends their work on performance outcome at the firm level (i.e. trade cost) to the national level (i.e. GDP per capita). The findings provide insights for firms to make location decisions, and policy makers to develop effective trade facilitation measures.

- Secondly, this study empirically validates the proposed model to establish the relationships between trade facilitation activities, and their associations with trade cost (through the validation of Hypotheses 2.1 and 2.2) and economic performance (through the validation of Hypotheses 3 and 5.1). TF-MA refers to functions that are performed or managed by a government to facilitate trade related activities, while TF-MI refers to functions that are performed or managed by business organizations to facilitate trade related activities. The association between TF-MA and TF-MI illustrate the importance of public-private partnerships (particularly for developing countries) in developing social capital to enhance TCE operations.

- Thirdly, policy makers at all levels often put forth favourable policies that aim to increase economic performance. Good economic performance is indicated by high spending per household which leads to increases in demand for consumer goods and subsequently retail activities. The development of TCEs can be a good means to enhance regional competitiveness. To boost the development of TCEs, policy makers formulate effective policies that develop social capital through the facilitation of trade and related activities. The confirmation of Hypothesis 4 illustrates the importance of formulating effective policies to reduce trade cost that would then increase regional competitiveness.

- Fourthly, the findings are useful for firms in making their location decision. It is important for TCE users to understand the consequences of a competent TCE (e.g., higher level TCEs lead to lower trade costs). TCEs affect the location decisions of international business operators. A successful TCE that has effective social capital to perform trading related activities has higher level of economic performance (as validated from Hypothesis 5.2). 
This study illustrates and validates the proposed theoretical model to seek answers to questions such as: What are the roles of trade facilitation at the macro-level and microlevel? Does trade facilitation influence the economic development of a region? What is the link between the development and economic performance of a TCE in a region? However, there are some limitations of this study. First, this study focuses on social capital. There are close relationship between human capital and social capital (Keeley 2007). The co-existence of these two capitals has not been examined in this study. Future research may conduct to investigate the co-existence of human and social capitals. The second limitation is the scope of this study. This study investigates the effect of trade facilitation activities on economic performance. Other variables (e.g. land cost, energy cost, labour cost, and cargo source). It is desirable to conduct future research to examine the impacts of other variables.

Competing interests

The authors declare that they have no competing interests.

Authors' contributions

YHVL, JC and KB carried out the TEC studies. All authors read and approved the final manuscript.

\section{Acknowledgements}

We are grateful to the reviewers for their helpful comments on earlier versions of this paper. This paper published outputs of an on-going research conducted by the authors. This project is supported in part by The Hong Kong Polytechnic University (Project A/C: G-YBEN \& G-YBH8).

\section{Author details}

${ }^{1}$ Department of Logistics and Maritime Studies, Shipping Research Centre, The Hong Kong Polytechnic University, Hung Hom, Hong Kong. ${ }^{2}$ City University London, London, UK.

Received: 31 July 2015 Accepted: 8 June 2016

Published online: 20 July 2016

\section{References}

Adger WN (2009) Social capital, collective action, and adaption to climate change. Econ Geogr 79(4):387-404

Adler PS, Kwon SW (2002) Social Capital: prospects of a new concept. Acad Manag Rev 27(1):17-40

Alcacer J, Chung W (2007) Location strategies and knowledge spillover. Manag Sci 53(5):760-776

Ang BW (2006) Monitoring changes in economy-wide energy efficiency: From energy-GDP ratio to composite efficiency index. Energy Policy 34:574-582

Anokhin S, Wincent J (2012) Start-up rates and innovation: A cross-country examination. J Int Bus Stud 43:41-60

Banerjee A, Marcellino M (2006) Are there any reliable leading indicators for US inflation and GDP growth. Int J Forecast 22:137-151

Barker W (1990) Market networks and corporate behavior. Am J Sociol 96:589-625

Bentler PM (1990) Comparative fit indexes in structural models. Psychol Bull 107:238-246

Bentler PM, Bonett DG (1980) Significant tests and goodness of fit in the analysis of covariance structures. Psychol Bull 88:588-60

Beugelsdijk S, Mudambi R (2012) MNEs ad border-crossing multi-location enterprises: The role of discontinuities in geographic space. Int J Bus Stud 44:413-426

Bollen KA (1986) Sample size and Bentler and Bonett's nonnormed fit index. Psychometrika 51:375-377

Bollen KA (1989) Structural Equations with Latent Variables. Wiley, NY

Bollen KA (1990) Overall fit in covariance structure models: Two types of sample size effects. Psychol Bull 107:256-259

Brouthers KD (2002) Institutional, cultural and transaction cost influences on entry mode choice and performance. J Int Bus Stud 33(2):203-221

Brouthers KD (2013) A retrospective on: Institutional, cultural and transaction cost influence on entry mode choice and performance. J Int Bus Stud 44(1):14-22

Brown JD (1996) Testing in language programs. Prentice Hall, NJ

Browne MW, Cudeck R (1993) Alternative ways of assessing model fit. In: Bollen KA, Long JS (eds) Testing Structural Equation Models. Sage, Beverly Hills

Burt RS (1997) The contingent value of social capital. Adm Sci Q 42:339-365

Byrne BM (1994) Structural equation modeling with EQS and EQS/Windows. Sage Publications, Thousand Oaks

Campbell DT (1959) Convergent and discriminant validation by the Multitrait-Multimethod Matrix (MTMM). Psychol Bull 56:81-105

Chen Y, Li H, Zhou LA (2005) Relative performance evaluation and the turnover of provincial leader in China. Econ Lett $88: 421-421$

Cheung G, Rensvold RB (2002) Evaluating goodness-of-fit indexes for testing measurement invariance. Struct Equ Model 9(2):233-255

Coleman JS (1998) Social capital in the creation of human capital. Am J Sociol 94:95-120 
Cronbach LJ (1951) Coefficient alpha and the internal structure of tests. Psychometrika 16(3):297-334

Eschenhach F, Hoekman B (2006) Services policy reform and economic growth in transition economies. Rev World Econ 142(4):746-764

European Commission (1996) Cohesion and competitiveness: trends in the regions. European Commission, Luxembourg Francois JH (1990) Producer services, scale, and the division of labor. Oxf Econ Pap 42(4):35-43

Ganotakis P, Love JH (2012) Export propensity, export intensity and firm performance: The role of the entrepreneurial founding team. J Int Bus Stud 42:693-718

Garrett G (2009) Capital mobility, trade, and the domestic policies of economic policy. Int Organ 49(4):657-687

Hair JF, Black WC, Babin BJ, Anderson RE, Tatham RL (2006) Multivariate Data Analysis., Pearson Prentice Hall

Hooper D, Coughlan J, Mullen MR (2008) Structural equation modelling: Guidelines for determining model fit. J Bus Res Methods 6:53-60

Hu L, Bentler M (1999) Cutoff criteria for fit indexes in covariance structure analysis: Conventional criteria versus new alternatives. Struct Equ Model 6(1):1-55

Kaplan D (2007) Structural Equation Modeling., Sage

Keeley B (2007) Human Capital: How what you know shapes your life., OECD

Kenny DA, McCoach DB (2003) Effect of the number of variables on measures of fit in structural equation modeling. Struct Equ Model 10:333-3511

Kline R (2011) Principles and Practice of Structural Equation Modeling., Guilford

Kline RB (1998) Principles and practice of structural equation modeling. Guilford Press, NY

Leana CR, Van Buren HJ (1999) Organizational social capital and employment practice. Acad Manag Rev 24:538-555

Loannou I, Serafeim G (2012) What drives corporate social performance? The role of national-level institutions. Int J Bus Stud 42:834-864

Lorenen M, Mudambi R (2013) Clusters, connectivity, and catch-up: Bollywood and Bangalore in the global economy. J Econ Geogr 13(3):501-534

Lun YHV, Browne M (2009) Fleet mix in container shipping operations. Int J Shipping and Trans Logis 1(2):103-118

Lun YHV, Cariou P (2009) An analytical framework for managing container terminals. Int J Shipping Trans Logis 1(3):419-436

Lun YHV, Lai KH, Cheng TCE (2010) Shipping and Transport Logistics. Springer, London

Lun YHV, Lai KH, Cheng TCE (2011a) Investigation of the influences of transport complex economy and political risk on freight transport growth. Int J Log Res Appl 14(5):285-296

Lun YHV, Lai KH, Cheng TCE (2011b) A descriptive framework for the development and operation of liner shipping network. Transp Rev 29(4):439-457

Lun YHV, Lai KH, Cheng TCE (2013a) An evaluation of green shipping network to minimize external cost in the Pearl River Delta region. Technol Forecast Soc Chang 80(2):320-328

Lun YHV, Wong CWY, Lai KH, Cheng TCE (2013b) Demand chain management in the container shipping service industry. Int J Prod Econ 141(2):485-492

Marshall A (1920) Principle of Economics. Palgrave Macmillan, London

Martin X (2013) Solving theoretical and empirical conundrums in international strategy research: Linking foreign entry mode choice and performance. J Int Bus Stud 44:28-41

McDonal AR, Ho HMR (2003) Principles and practice in reporting statistical equation analyses. Psychol Methods 7(1):6482

Miller RL, Brewer JD (2003) Research Methods., Sage

Nahapiet J, Ghoshal S (1998) Social capital, intellectual capital, and organizational advantage. Acad Manag Rev 23:242266

Pennar K (1997) The ties that lead to prosperity: The economic value of social bonds is only beginning to be measured. Bus Week 15:153-155

Poetes A (1998) Social capital: Its origins and application in modern sociology. Annu Rev Sociol 24:1-24

Porte A (1998) Social capital: Its origins and applications in modern sociology. Annu Rev Sociol 24:1-24

Portugal-Perez A, Wilson JN (2012) Export performance and trade facilitation reform: Hard and soft infrastructure. World Dev 40(7):1295-1307

Rawski TG (2001) What is happening to China's GDP statistics? China Econ Rev 12:358-357

Richardson GB (1972) The organization of industry. Econ J 82:883-896

Robbins B, Pettinicchio D (2012) Social capital, economic development, and homicide: A cross-national investigation. Soc Indic Res 105:519-540

Rodrigue JP, Notteboom T (2010) Foreland-based regionalization: Integrating intermediate hubs with port hinterlands. Res Transp Econ 27:19-29

Samdefir RL, Laumann EO (1988) A paradigm for social capital. Ration Soc 10:481-501

Schotter A, Beamish PW (2013) The hassle factor: An explanation for managerial location shunning. J Int Bus Stud 44: 521-544

Schumacker RE, Lomax RG (2004) A beginner's quide to structural equation modeling. Lawrence Erlbaum Associates, Mahwah Tabachnick BG, Fidell LS (2001) Using Multivariate Statistics, Needham Heights. Allyn \& Bacon, MA

Tsai W, Ghoshal S (1998) Social capital and value creation: The role of inter-firm networks. Acad Manag J 41(4):464-476

Uzzi B (1997) Social structure and completion in inter-firm networks: The paradox of embeddedness. Adm Sci Q 42:35-67

West SG, Taylor AB, Wu W (2012) Model fit and model selection in structural equation modeling. In: Hoyle RH (ed) Handbook of Structural Equation Modeling. Guilford, New York

Widaman KF, Thompson JS (2003) On specifying the null model for incremental fit indices in structural equation modeling. Psychol Methods 8(1):16-37

Winters LA (2004) Trade liberation and economic performance. Econ J 114:4-21

Woolcock M, Narayan D (2000) Social capital: Implications for development theory, research and policy. World Bank Res Obs 15(2):1-49 